RESEARCH

\title{
Toward the Construction of Integrated Physical and Genetic Maps of the Mouse Genome Using Interspersed Repetitive Sequence PCR (IRS-PCR) Genomics
}

\author{
Kent W. Hunter, ${ }^{1,4}$ Laura Riba, ${ }^{1}$ Leo Schalkwyk, ${ }^{2}$ Matthew Clark, ${ }^{2}$ \\ Sergei Resenchuk, ${ }^{2}$ Alicia Beeghly, ${ }^{2}$ Jenny Su, ${ }^{1}$ Felix Tinkov, ${ }^{1}$ \\ Pang Lee, ${ }^{1}$ Elango Ramu, ${ }^{1}$ Hans Lehrach, ${ }^{2,3}$ and David Housman ${ }^{1}$
}

${ }^{1}$ Center for Cancer Research, Massachusetts Institute of Technology, Cambridge, Massachusetts 02139;

${ }^{2}$ Imperial Cancer Research Fund, Genome Analysis, Lincoln's Inn Fields, London, WC2A 3PX UK

Using two recently developed techniques, IRS-PCR YAC walking and IRS-PCR genotyping, a frameworkintegrated physical and genetic map of the mouse genome was constructed. The map consists of 821 contigs, containing 7746 YAC clones originating from three different YAC libraries. Three hundred eighty of the contigs have been anchored to the genetic map. Approximately $16 \%$ of the physical length of the mouse genome is estimated to be represented.

A major task in developing our understanding of the human genome is the creation of integrated physical and genetic maps of the human genome and selected model systems (Chapman et al. 1993; Collins and Galas 1993). One major approach strategy to realize this goal has been the development and use of PCR-based sequencetagged sites (STSs) as anchors for genetic and physical maps. Simple sequence length polymorphisms (SSLPS) have been the primary source of STS-based genetic markers in humans (Murray et al. 1994) and mice (Cornall et al. 1991; Watson et al. 1992; Copeland et al. 1993; Dietrich et al. 1992, 1993, 1994; Hunter et al. 1993). STS content mapping of libraries of yeast artificial chromosomes (YACs; Burke et al. 1987) has been a primary means of physical mapping (for review, see Schlessinger et al. 1991; Chumakov et al. 1992; Foote et al. 1992; Cohen et al. 1993; Vetrie et al. 1994). The recent development of two techniques, based on interspersed repetitive sequence PCR (IRS-PCR; Nelson et al. 1989), has permitted the development of an alternative, complementary strategy for integrated physical and genetic

\footnotetext{
${ }^{3}$ Present address: Max-Planck-Institut für Molekulare Genetik, Berlin-Dahlem, D14195, Germany.

${ }^{4}$ Corresponding author.

E-MAIL kent@wccf.mit.edu; FAX (617) 253-5202.
}

mapping in the mouse genome. IRS-PCR-based strategies permit rapid, low-cost, and accurate genotyping (McCarthy et al. 1995) and screening of YAC libraries (Hunter et al. 1994; Liu et al. 1995; Aburatani et al. 1996; Qin et al. 1996).

Both genetic and physical mapping using IRS-PCR depend on the use of PCR primers, which permit amplification of DNA sequences located between two interspersed repetitive elements oriented in opposite directions in the genome separated by a distance that is within range of a conventional PCR reaction. Individual loci can be assayed by isolating single-copy sequences located between pairs of repetitive elements oriented in this manner and using each of these sequences as a hybridization probe against IRSPCR products from a large number of individuals or YAC pools in a dot-blot format. In the mouse the $\mathrm{B} 1$ repeat element has proved most favorable for analysis of this type.

IRS-PCR products can be mapped genetically by taking advantage of the genetic differences among mouse species or strains in the amplification of specific IRS-PCR products. Segregation of an amplification polymorphism is detected easily among a panel of DNAs derived from an interspecific backcross panel by hybridizing a probe representing an individual IRS-PCR product from the nonrecurrent parent to filters of gridded IRS- 


\section{IRS-PCR PHYSICAL MAPPING OF THE MOUSE GENOME}

PCR products of individual backcross animals. High resolution mapping is possible by genotyping large numbers of animals per filter, and a single investigator is capable of screening hundreds of clones per week (McCarthy et al. 1995; Ramu et al. 1996). The resulting map consistently replicates the results obtained by conventional methods and therefore produces a map with high confidence (McCarthy et al. 1995; Ramu et al. 1996). To date, $>400$ amplification polymorphism loci have been mapped (McCarthy et al. 1995; Ramu et al. 1996).

IRS-PCR can also be used to detect YAC overlap and construct contigs by hybridization. Using the unique sequences that lie between two B1 repeat sequences, a PCR product from one YAC is used as probe on filters containing gridded sets of inter-B1 products derived from the pools for the three-dimensional screening arrays of the mouse YAC libraries. Overlapping clones are detected by hybridization to the $x, y$, and $z$ coordinates of any other YAC that amplifies the same IRS-PCR product. The utility of this technique was demonstrated by the construction of a $\sim 5-\mathrm{cM}$ contig on mouse chromosome 1 (Hunter et al. 1994).

When combined, these techniques permit the highly efficient generation of an integrated genetic and physical map of the mouse genome because randomly cloned IRS-PCR products are screened simultaneously for contig generation and amplification polymorphism. Although only $25 \%$ of random inter-B1 products demonstrate amplification polymorphism (McCarthy et al. 1995; Ramu et al. 1996), a sufficiently large number of loci are available to produce an integrated map of high marker density. The major advantage to the IRS-PCR approach is that it permits the simultaneous screening of multiple libraries or interspecific backcrosses in the same hybridization while avoiding the necessity of running gels or sequencing each probe.

As a demonstration of the utility of this strategy, we present here a framework-integrated physical and genetic map of the mouse genome, consisting of 7746 individual YAC clones from three different YAC libraries in 821 contigs. Forty six percent of the contigs have been anchored genetically (380 of 821 contigs) The contigs described are estimated to cover $\sim 16 \%$ of the mouse genome.

\section{RESULTS}

Integrated physical and genetic mapping was performed by hybridizing filters representing the three-dimensional screening strategies for the St. Mary's Hospital (Chartier et al. 1992), Imperial Cancer Research Foundation (ICRF) (Larin et al. 1991), Massachusetts Institute of Technology (MIT)/Whitehead (Kusumi et al. 1993) YAC libraries, and the IRS-PCR genetic mapping filters of the Jackson Laboratory BSS interspecific backcross panel (Rowe et al. 1994; McCarthy et al. 1995) simultaneously with individual clones of the probe library (for examples, see Fig. 1).

A total of 1903 probes were analyzed, the YAC coordinates and haplotype data manually scored, and the YAC addresses and accompanying locus designations entered into a Filemaker Pro data base. Contigs were identified by analyzing the YAC data with the computer program probeorder (Mott et al. 1993), which uses simulated annealing to order probes based on shared positive YACs and then fits the YACs to the probe order. For this first generation analysis, incomplete and ambiguous addresses were omitted and relatively permissive criteria for contig assembly were used. A single shared positive YAC is accepted as a link between probes, and clones apparently lying in four or more contigs are disregarded. This set of contigs gives an idea of the progress of the project but will contain false links and should be regarded as the starting point of a more detailed analysis that also considers genetics and other data. A total of 7746 individual YAC clones were identified from the three libraries in 821 contigs. Of the YACs detected, 3436 were identified unambiguously (44\%). The ambiguity of the remaining YACs resulted in either detection of only two of the three coordinates or caused by the presence of more than one positive clone in a set of coordinate pools. Approximately $46 \%$ ( 380 of 821 ) of the contigs were anchored to the genetic map by amplification polymorphisms (Fig. 2). Contigs were identified on every chromosome except the $\mathrm{Y}$ chromosome, as all of the YAC libraries were generated from female mice. The remaining contigs were identified by nonpolymorphic IRS-PCR products, and their genomic location is not known. Many of these contigs are expected to merge with genetically anchored contigs as the density of amplification polymorphism probes increases.

The distribution of the number of probes hybridizing per unambiguous YAC clones is shown in Figure 3. As expected, the majority of clones (73\%) were detected by only a single probe. The generation of a number of small extended con- 


\section{HUNIER ET AL.}

A
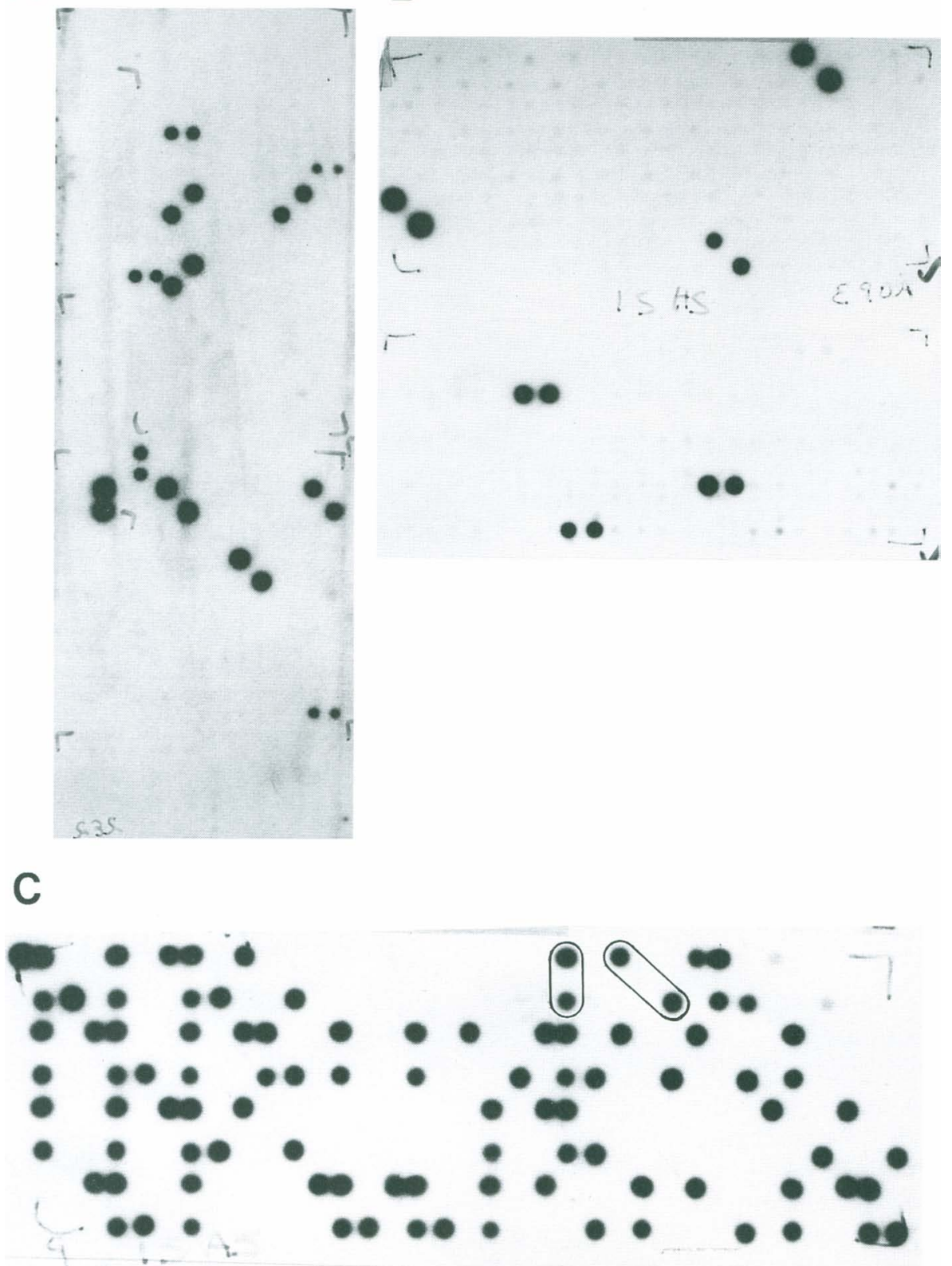

Figure 1 Example of integrated IRS-PCR genetic and physical screen. (A) IRSPCR YAC filter of the MIT/Whitehead Library. (B) IRS-PCR YAC filter of the St. Mary's Hospital and ICRF libraries. (C) IRS-PCR genetic mapping filter of the Jackson Laboratory BSS interspecific backcross panel. Samples on the YAC filters are in duplicate, arrayed in both diagonals, horizontally or vertically. Addresses of individual clones are determined by intersection of the three coordinate pools represented on the filter by paired hybridization signals, with the same orientation. The Jackson Laboratory BSS panel samples are duplicated either in the right-to-left diagonal or in the vertical. Representitive samples are circled. Animals heterozygous for the $\mathrm{C} 57 \mathrm{BL} / 6$ allele are represented by positive hybridization signal, homozygous $M$. spretus animals do not hybridize.

tigs was observed, however, as indicated by clones detected by several probes. Clones hit by more than two or three probes might be attrib- utable to the presence of multiple isolates of the same probe that escape the probe library prescreen and the subsequent probe-toprobe analysis.

The efficiency of IRSPCR screening of the various libraries was determined by comparing the number of clones detected compared with the number predicted by the number of genome equivalents screened. The distribution of clones detected per probe was determined by comparing the number of YACs detected in each library from each of 100 genetically independent probes to the predicted Poisson distribution (Fig. 4). Genetically independent clones were used rather than the whole data set to eliminate any possible errors caused by the presence of multiple isolates of the same probe. No significant deviation from the predicted curve was observed in any of the three libraries.

Examination of the contigs constructed by genetically polymorphic loci identified a significant number of putatively chimeric clones. To determine whether these represented legitimate chimeras or were attributable to clerical or experimental error, 52 YACs, with representatives from all three libraries, were IRS-PCR amplified, and the products dot blotted and hybridized with the putatively positive probes. Approximately $70 \%$ (17 of 24 ) of the probes assayed detected the predicted YACs (Fig. 5), including several putatively triply chimeric clones. The remaining 30\% 
IRS-PCR PHYSICAL MAPPING OF THE MOUSE GENOME

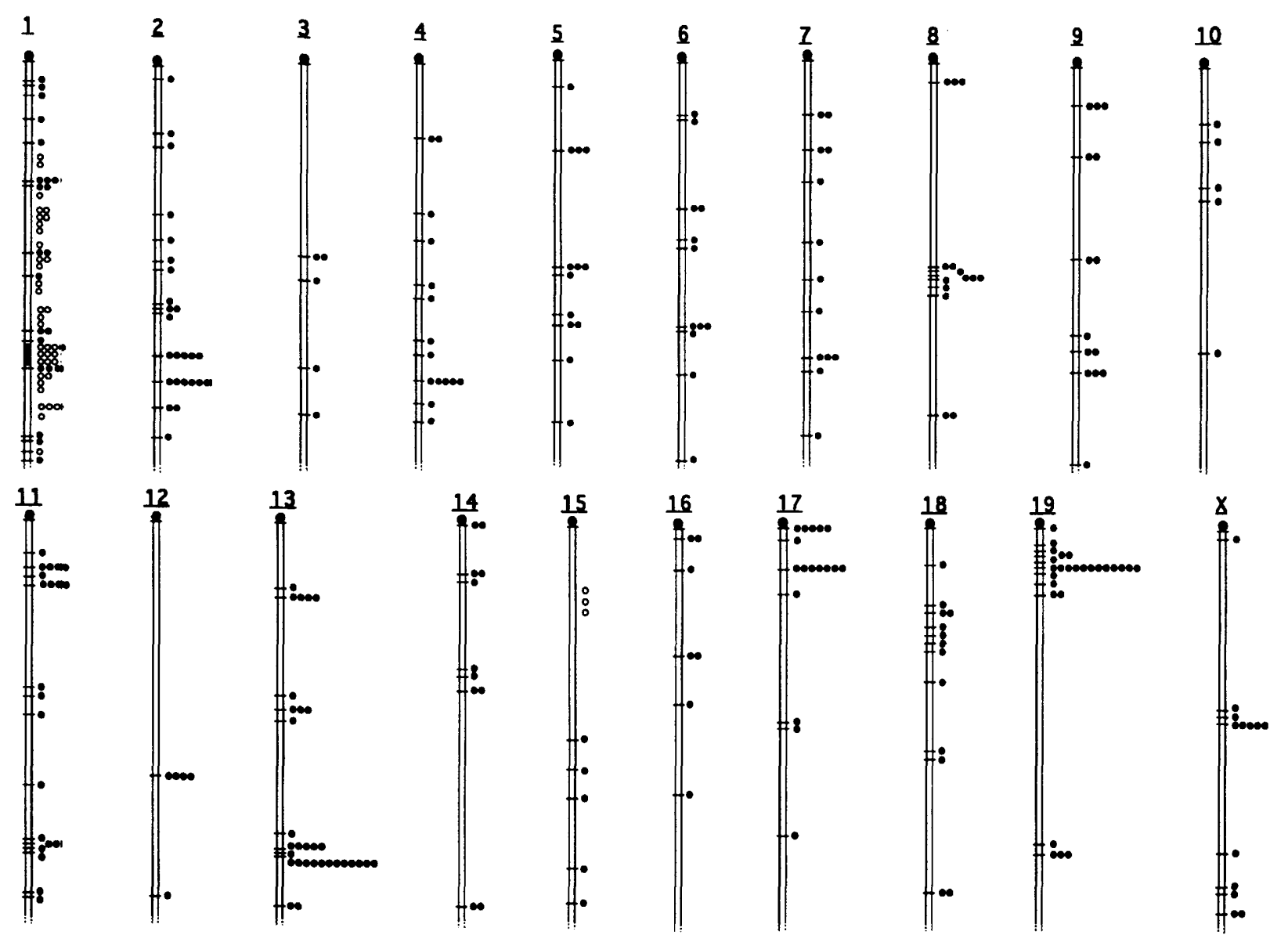

Figure 2 Schematic representation of the genetically anchored YAC contigs. Filled circles indicate contigs identified by IRS-PCR contiging. Open circles indicate contigs identified by STS content mapping. The filled box on chromosome 1 represents the previously described contig (Hunter et al. 1994).

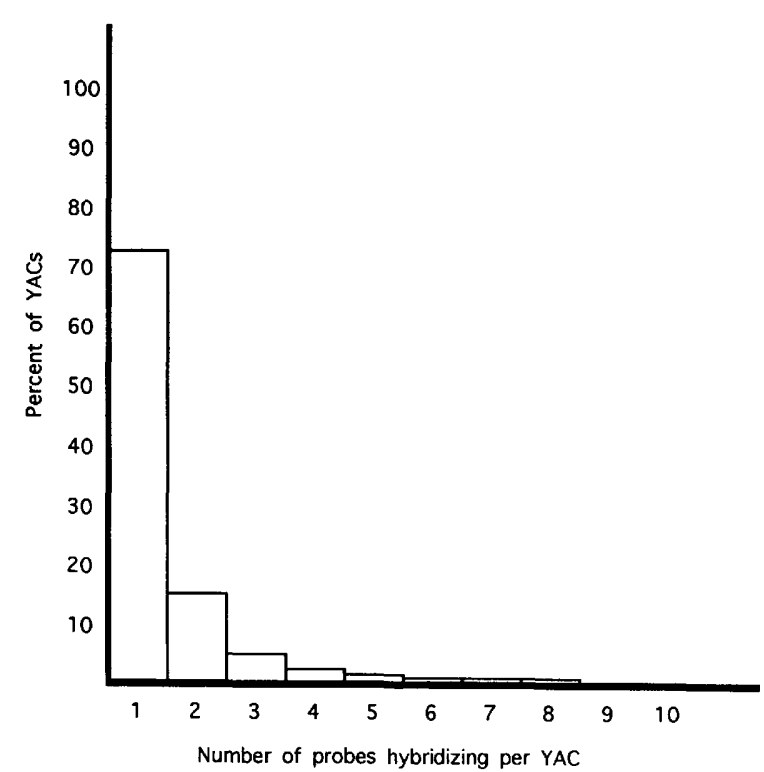

Figure 3 Distribution of the number of probes hybridizing to the unambiguously defined YACs in the data base. result either from clerical errors or from the internal deletion of the IRS-PCR product during clonal expansion (Hunter et al. 1994).

The genome coverage of this set was calculated several ways. A simplistic estimate of the genome covered was made by calculating the percent of the YACs in the MIT/Whitehead library that were detected by the probes used. Of 18,432 clones screened, 3070 were assembled into contigs, indicating that $-16.6 \%$ of the YAC clonable genome had been covered. The calculation was also performed by assuming $600 \mathrm{~kb}$ of contiguous DNA (50\% overlap of YACs, with average size of $400 \mathrm{~kb}$ ) was covered by each of 821 contigs. On the basis of these calculations, (821 contigs $\times 600,000$ bp per contig/ $3 \times 10^{9}$ bp per genome), $-16.4 \%$ of the physical length of the mouse genome should be represented. 


\section{HUNTER ET AL.}
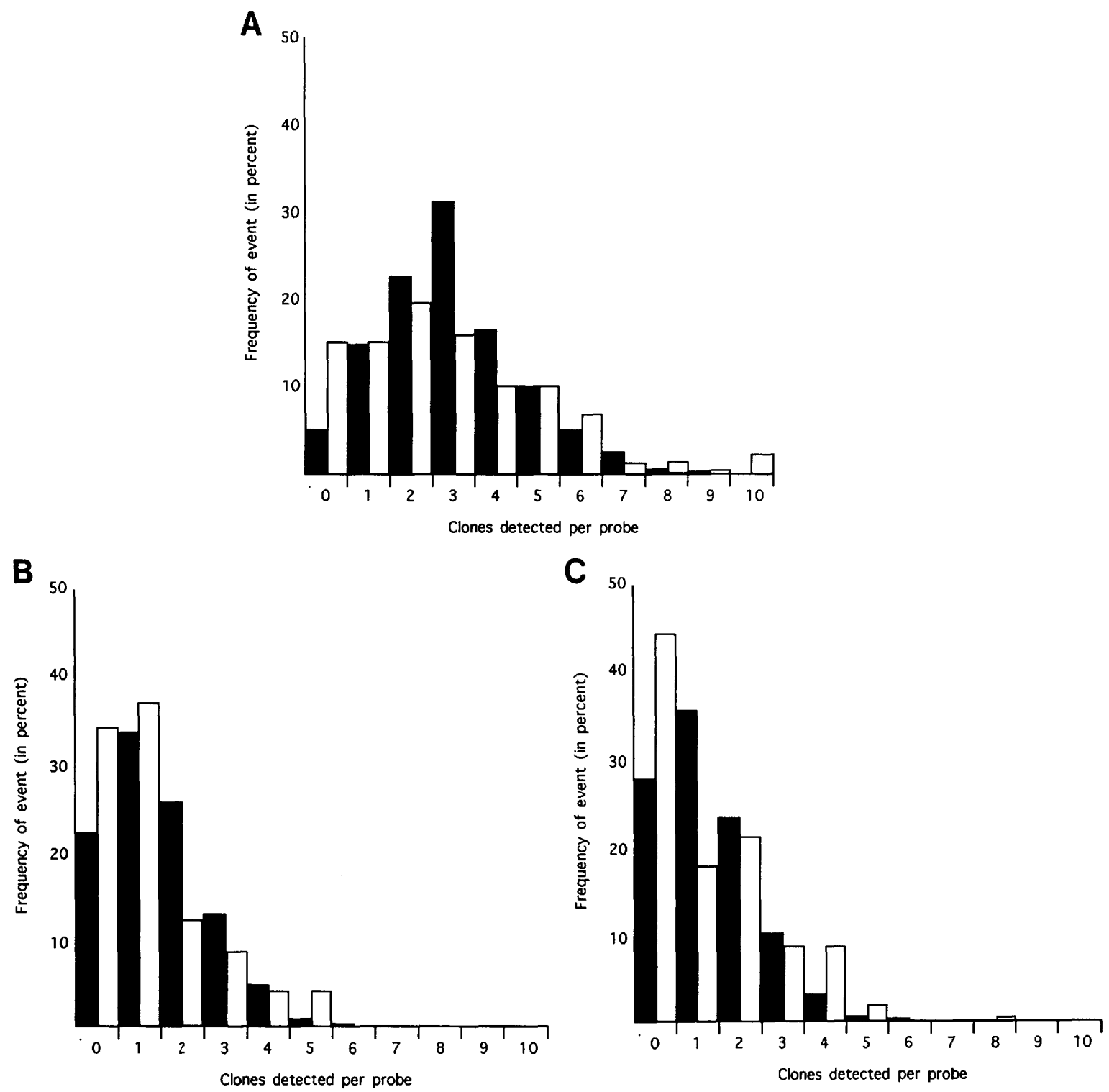

Figure 4 Comparison of the predicted and observed clone distribution. $(A)$ MIT/Whitehead library; $(B)$ St. Mary's Hospital library; (C) ICRF library.

\section{DISCUSSION}

The data presented here comprise the first largescale effort to construct a contiguous physical map of the mouse genome. A significant portion of the mouse genome is represented, with clones originating from three independently derived YAC libraries. In many cases the contigs identified in this study will enable researchers to rapidly identify clones that extend preexisting contigs or to increase coverage of a particular region. The use of three different libraries will be particularly important in regions that are not amenable to YAC cloning. In a number of cases, it was ob- served that regions not represented in one or two of the libraries were often present in the third library, enabling extension of contigs into regions that were refractory to extension in a single library. It is anticipated that a majority of the mouse genome can be assembled into contigs by this strategy, as a similar strategy was used for the construction of contigs on human 3p21-14 demonstrated that this technique is useful for contig assembly and extension even in regions of relatively low repetitive element density (Aburatani et al. 1996).

In addition, this strategy has resulted in a sig- 


\section{IRS-PCR PHYSICAL MAPPING OF THE MOUSE GENOME}

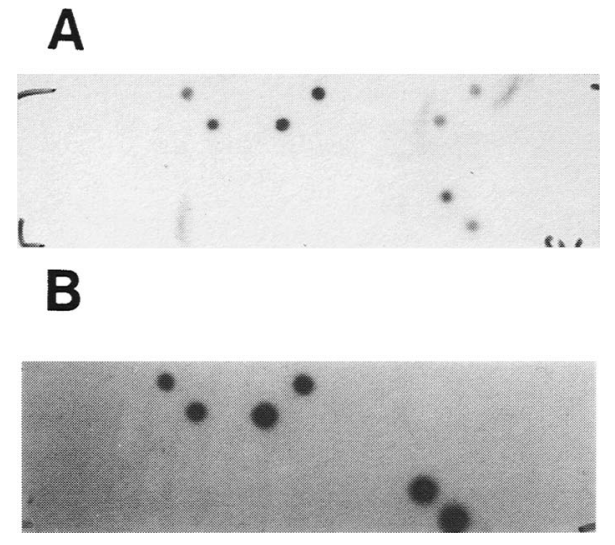

Figure 5 Example of the individual chimera analysis. Fifty two individual YAC clones were amplified with the B1 primer, the products spotted on filters in duplicate, gridded in either diagonal, and hybridized with D3Hun2 (A) or D8Hun8 (B).

nificant portion of the YAC contigs identified to be anchored to the genetic map (Fig. 2). Although only $46 \%$ of the contigs were directly localized genetically, additional contigs can be localized by overlap with genetically anchored contigs (data not shown). As the density of genetically localized contigs increases, the unlocalized contigs will be gradually incorporated into a contiguous physical map by physical linkage to flanking loci. Because the data presented here rely primarily on amplification polymorphisms to link the physical and genetic maps, the integration with an STS-based contig map can only be achieved by identification of clones that are common between STS-based and amplification polymorphism contigs. Investigators interested in using these data to extend existing contigs are advised to search the data base with clones at the ends of their preexisting contigs to determine whether the clones have been identified and incorporated into contigs. It is anticipated that integration of the physical maps will be facilitated as the density of microsatellite type on the Jackson Laboratory BSS panel is increased, and the relationship between the microsatellites and the amplification polymorphism loci is resolved. To further integration of the various physical and genetic maps, all of the Hun loci clones used in this study will be deposited with Research Genetics for distribution. The nonpolymorphic probes are available to the community by contacting us.

Examination of the integrated physical and genetic map revealed clustering of loci and their associated contigs. Although some apparent clustering might be explained by duplicate probes that escaped detection during our analysis, the majority of events leading to clustering are independent as determined by probe-to-probe hybridization (data not shown) and identification of independent YAC sets. In addition, sequence analysis of clustered loci on chromosomes 13 and 19 have demonstrated that with two exceptions, the loci are independent (G. Cox and P. Gros, pers. comm.). The apparent cluster may be regions that are inverted between C57BL/ 6 and Mus spretus and, hence, give no recombination over large physical distances and/or are regions of high B1 density (Boyle et al. 1990). Further studies will be required to address these issues.

Comparisons of IRS-PCR physical mapping and STS content mapping reveal that the capability of the two techniques to detect clone overlap are roughly equal. In our hands, the efficiency of screening the St. Mary's hospital library by STS content mapping was equivalent to that of IRS-PCR YAC screening (K. Hunter, unpubl.). Independent researchers have observed similar efficiencies in the MIT/Whitehead library (C. Fletcher, pers. comm.). We have also been able to replicate the construction of a number of contigs constructed by conventional STS content screening (J. Weber and M. Meissler; C. Fletcher; L. Zelter; all pers. comm.). The reproducibility of the technique is also excellent. Identical results were obtained with probes that were subsequently shown to be identical by clone-to-clone screening.

A generic problem with strategies based on the three-dimensional screening system is the high degree of ambiguous clone identification. In particular, the existence of two positive clones in a set of three-dimensional coordinate pools can result in ambiguous scorings. This has been a significant issue in this study, particularly with the ICRF library because of the high genome complexity of plate stacks used to generate the coordinate pools ( $\sim 1.5$ genome equivalent). To reduce this problem and hopefully to increase the efficiency of screening, a new set of coordinate pools defining the ICRF library of lower genomic complexity has been generated and future analysis will be performed using filters with the new ICRF coordinate pools. This will reduce the probability of having multiple positive clones in the same set of coordinate pools and thus reduce the overall ambiguity of the data base. Deletion of the target sequence in one of the coordinate pools during 


\section{HUNTER ET AL.}

three-dimensional pool generation can be a problem, with both STS and B1 PCR screening resulting in ambiguous YAC addresses. We have included all ambiguous data in our data base, as the ambiguous clones still represent a significant reduction of effort to identify a specific clone. Eventually, as the density of probes increases, the identities of many of these ambiguously defined clones will be resolved.

The analysis of the putative chimeric YACs yielded several interesting results. As expected, a number of YACs hybridized with more than one genetically independent probe, suggesting that they were true chimeras. The clones that did not hybridize to the relevant probes can be explained by either clerical error or by deletion of the interB1 product. Our analysis of the mouse chromosome 1 contig demonstrated that although IRSPCR YAC walking reproducibly detected the same set of YACs and end-clone analysis (Riley et al. 1990) confirmed overlap, clones often had deleted the inter-B1 product during the generation of high molecular weight DNA (Hunter et al. 1994), presumably because of the intolerance of inverted repeats in yeast (Gordenin et al. 1993). Therefore, most of the nonhybridizing clones probably fall into this category. Unexpectedly, multiple members of several contigs hybridized with two genetically independent probes, suggesting that the clones might be chimeric for the same portions of the genome (Fig. 5). Duplicate isolation of the same YAC could explain such results. However, results of this type were observed in contigs with clones originating from two libraries, and therefore eliminating duplication isolation as an explanation for this finding. The possible duplication of a genomic region followed by divergence of the genetically separated probes would be consistent with these observations. Regions of significant genetic duplication have been observed in human YAC contig generation (V. Stanton, pers. comm.). Further analysis to investigate these genomic regions in the mouse is clearly warranted.

To complete the mouse physical genome map by IRS-PCR will require $\sim 10,000$ evenly distributed probes. Isolation of probes directly from a PCR of whole genomic DNA has provided a genetically anchored framework physical map. To proceed to completion, alternative sources of B1 PCR products, which provide as even a distribution throughout the genome as possible, would be most useful. Generation of IRS-PCR products from flow-sorted chromosomal DNA, randomly selected YACs, bacterial artificial chromosome (BACs), or cosmid clones will be an excellent way to achieve this goal, as well to anchor the YAC contigs to framework cosmid or BAC maps.

\section{METHODS}

\section{Configuration of the YAC Libraries}

The three-dimensional pooling scheme for the St. Mary's Hospital YAC library (Chartier et al. 1992) is described in Hunter et al. (1994). The ICRF library pools were arrayed essentially as described (Hunter et al. 1994; G. Argryopoulus, pers. comm.). The three-dimensional configuration of the MIT YAC library is described in Kusumi et al. (1993).

\section{Generation of High Molecular Weight DNAs and IRS-PCR Walking Filters}

Generation of YAC three-dimensional pool DNA and production of the YAC IRS-PCR walking filters is described in Hunter et al. (1994).

\section{Generation of IRS-PCR Genotyping Filters}

Fifty nanograms of each of the Jackson Laboratory BSS interspecific backcrosses were amplified and spotted essentially as described (Hunter et al. 1994).

\section{IRS-PCR Probe Library Generation}

Fifty nanograms of C57BL/6J genomic DNA was amplified with the $\mathrm{B} 1 \mathrm{MvsCH}$ primer essentially as described (Hunter et al. 1994). The products were then enriched for C57BL/ 6]-specific products by subtraction with $M$. spretus products, based on representation difference analysis (RDA, Lisitsyn et al. 1993). The PCR reaction was phenol/ chloroform extracted, precipitated, washed, dried, and resuspended in TE. Ten micrograms of PCR products was digested to completion with EcoR2 (Stratagene, Palo Alto, CA), and the primers removed by Centricon-100 (Amicon, Beverly, MA) purification. The JBglCla adaptor was ligated by incubating $2 \mu \mathrm{g}$ of EcoR2-digested product with $15 \mu \mathrm{l}$ each of JBgICla-24 and JEcoR2Cla-13 oligonucleotides, 6 $\mu l$ of $10 \times$ T4 DNA ligase buffer (New England Biolabs, Beverly, MA) in $60-\mu \mathrm{l}$ final volume, at $65^{\circ} \mathrm{C}$ for $20 \mathrm{~min}$, cooling slowly to $14^{\circ} \mathrm{C}$, adding 800 units of T4 DNA ligase (New England Biolabs), and incubating overnight at 12 $16^{\circ} \mathrm{C}$. One microgram of linkered product was then precipitated with $40 \mu \mathrm{g}$ of $M$. spretus B1MvsCH-amplified products, washed in $70 \%$ ethanol, dried, resuspended in 4 $\mu \mathrm{l}$ of $30 \mathrm{~mm}$ EEPS ( $\mathrm{pH} 8.0$ ), $3 \mathrm{~mm}$ EDTA, and overlayed with mineral oil. The reaction was denatured at $98^{\circ} \mathrm{C}$ for 5 $\mathrm{min}$, and $1 \mu \mathrm{l}$ of $5 \mathrm{M} \mathrm{NaCl}$ was added, incubated at $67^{\circ} \mathrm{C}$ for $>20 \mathrm{hr}\left(\mathrm{C}_{0} \mathrm{t}\right.$ value $\left.\geqslant 36 \mathrm{~mm} / \mathrm{sec}\right)$, and diluted with $390 \mu \mathrm{l}$ of TE. Forty microliters of the diluted hybridization reaction was extended by incubating at $70^{\circ} \mathrm{C}$ in $50 \mathrm{~mm} \mathrm{KCl}, 10 \mathrm{~mm}$ Tris ( $\mathrm{pH} 8.3$ ) $1.5 \mathrm{~mm} \mathrm{MgCl}_{2}, 200 \mu \mathrm{M}$ dNTPs, 15 units of Taq polymerase to a final reaction volume of $400 \mu$ l. Ten mi- 


\section{IRS-PCR PHYSICAL MAPPING OF THE MOUSE GENOME}

croliters of $20 \mu \mathrm{M} \mathrm{JBglCla-24}$ was added, and the reaction cycled 10 times essential as described (Hunter et al. 1994). The reaction was phenol/chloroform extracted, precipitated, washed in $70 \%$ ethanol, dried, and resuspended in $35 \mu \mathrm{l}$ of $\mathrm{ddH}_{2} \mathrm{O}$. Four microliters of $10 \times$ mung bean nuclease buffer and 10 units of mung bean nuclease (New England Biolabs) were added, and incubated for $30 \mathrm{~min}$ at $30^{\circ} \mathrm{C}$. The reaction was stopped by the addition of $160 \mu$ ] of $50 \mathrm{~mm}$ Tris (pH 8.9) and incubating at $98^{\circ} \mathrm{C}$ for $5 \mathrm{~min}$. Forty microliters of the nucleased product was used as template for a $400-\mu l$ PCR reaction using the JBglCla-24 primer as described (Hunter et al. 1994). The PCR reaction was phenol/chloroform extracted, precipitated, washed, dried, resuspended in TE, digested with ClaI (New England Biolabs), and subcloned into pBluescript $\mathrm{KS}(-)$, (Stratagene, Palo Alto, CA). A total of 1536 clones were isolated and arrayed in 96-well dishes. The complexity of the probe library was estimated by labeling 96 random IRS-PCR clones, pooling the probes, and hybridizing this pool to gridded filters representing the library. Approximately 900 $(60 \%)$ clones did not hybridize to the pooled probes and were assumed to be either single copy or infrequently repeated. Clones that hybridized to the complex pooled probe were excluded from further analysis.

\section{Hybridization and Washing Conditions}

Individual clones were amplified with vector-specific primers directly from bacterial cultures under the following conditions: $50 \mathrm{~mm} \mathrm{KCl}, 10 \mathrm{~mm}$ Tris ( $\mathrm{pH} 8.3$ ), $1.5 \mathrm{~mm}$ $\mathrm{MgCl}_{2}, 200 \mu \mathrm{M}$ dNTPs, $0.5 \mu \mathrm{M}$ each SKNot and KSXho, 1 unit of Taq polymerase to a final reaction volume of $20 \mu \mathrm{l}$ for $5 \mathrm{~min}$ at $94^{\circ} \mathrm{C}, 30$ cycles each of $10 \mathrm{sec}$ at $94^{\circ} \mathrm{C}, 30 \mathrm{sec}$ at $55^{\circ} \mathrm{C}$, and $60 \mathrm{sec}$ at $72^{\circ} \mathrm{C}$, followed by 5 min at $72^{\circ} \mathrm{C}$, and gel-purified through low melting temperature agarose (FMC, Rockland, MD). Probes were labeled in $10-\mu \mathrm{l}$ reactions by the random oligonucleotide labeling method (Feinberg and Vogelstein 1984) in 96-well format. Labeling reactions were incubated $90-120 \mathrm{~min}$ at $37^{\circ} \mathrm{C}$, diluted with $40 \mu \mathrm{l}$ of TE, denatured, and the unpurified probe added directly into the hybridization solution. Hybridizations were performed in $5 \mathrm{ml}$ of hybridization solution [50\% deionized formamide (Fluka, Buchs, Switzerland), 10\% dextran sulfate (Pharmacia, Piscataway, NJ), $2 \times$ SSC, $1 \%$ SDS, $1 \mathrm{~mm}$ EDTA] at $42^{\circ} \mathrm{C}$ in $30-\mathrm{ml}$ Sarstedt tubes on a bacterial wheel. Filters were washed once at room temperature in $2 \times \mathrm{SSC}, 0.1 \% \mathrm{SDS}, 1 \mathrm{~mm}$ sodium pyrophosphate for $15 \mathrm{~min}$ and once in $0.2 \times \mathrm{SSC}, 0.1 \% \mathrm{SDS}, 1 \mathrm{~mm}$ sodium pyrophosphate at $65^{\circ} \mathrm{C}$ for $60 \mathrm{~min}$, and exposed on film for $12-72 \mathrm{hr}$ with intensifying screens.

\section{Genetic Analysis}

Polymorphic clones were scored manually, the data entered into the Jackson Laboratory data base, and analyzed using the program MapManager v2.6 (Manly 1993). D_Hun data can be accessed on the Jackson BSS mapping panel through the World Wide Web via the Jackson Laboratory Home Page (http://www.jax.org), by e-mail to lbr@aretha.jax.org, or in MGD with accession numbers (McCarthy et al. 1995).

\section{Contig Analysis}

YAC contig data were scored manually and the data en- tered into a Filemaker Pro data base, which is available by contacting us. These data were filtered and converted into well file format (Mott et al. 1993) using a series of awk scripts and assembled into contigs using the program probeorder (Mott et al. 1993).

\section{Oligonucleotides}

Oligonucleotides used in this study are as follows: JBglCla24, 5'-ACCGACGTCGACTATCGATGAACA-3'; JECoR2Cla13, 5'-CCAGGTGTTCATC-3'; KSXho, 5'-CCCTCGAGGTCGACGGTATCG-3'; SKNot， 5'-GCGGCCGCTCTAGAACTAGTGGATC-3'; and B1MvsCH, 5'-AGTTCCAGGACAGCCAGGG-3' (Hunter et al. 1994).

\section{Isolation of IRS-PCR Probes From Individual YAC Clones}

IRS-PCR probes were isolated from individual YAC clones in 96-well plates as follows. Twenty microliters of YAC glycerol stocks was spun at $1500 \mathrm{rpm}$ in a Sorval RT6000 for $5 \mathrm{~min}$ in Costar $\mathrm{V}$-bottom polycarbonate plates. The supernatant was removed by flicking the plate, blotting with a paper towel, the cells resuspended in $20 \mu \mathrm{l}$ of TE, 6.7 $\mathrm{mM} \beta \mathrm{ME}$, and $1 \mathrm{mg} / \mathrm{ml}$ of yeast lytic enzyme and incubated $37^{\circ} \mathrm{C}$ for $60 \mathrm{~min}$. Ten microliters of TE, 0.3\% SDS, $150 \mathrm{~mm}$ of $\mathrm{NaCl}$, and $100 \mathrm{ng} / \mathrm{ml}$ of proteinase $\mathrm{K}$ was added, and the plate was incubated $37^{\circ} \mathrm{C}$ for $>2 \mathrm{hr}$. The DNA was precipitated by adding an equal volume of isopropanol and centrifuging for $5 \mathrm{~min}$ at $2000 \mathrm{rpm}$. The DNAs were washed twice with $70 \%$ ethanol, dried for $5 \mathrm{~min}$ at $80^{\circ} \mathrm{C}$ under vacuum, resuspended in $20 \mu \mathrm{l}$ of TE, and amplified in a $20-\mu l$ reaction under the following conditions: $11 \times$ Deep Vent buffer (New England Biolabs), $0.5 \mu \mathrm{M}$ B1MvsCH primer, $5 \mu \mathrm{M} \mathrm{MgCl}_{2}$ final concentration, $100 \mu \mathrm{M}$ dNTPs, 0.5 units of Deep Vent exo $]$. The cycling conditions were $94^{\circ} \mathrm{C}$ for $3 \mathrm{~min}, 30$ cycles each of $94^{\circ} \mathrm{C}$ for 10 $\mathrm{sec}, 53^{\circ} \mathrm{C}$ for $30 \mathrm{sec}, 72^{\circ} \mathrm{C}$ for $30 \mathrm{sec}$, followed by $5 \mathrm{~min}$ at $72^{\circ} \mathrm{C}$. Individual probes were isolated by electrophoresis through $2 \%$ LMT agarose.

\section{ACKNOWLEDGMENTS}

We thank Mary Barter and Lucy Rowe for assistance in the genetic analysis, and Ken Paigen for critical reading of this manuscript. This work was supported in part by U.S. Public Health Service grant 1-F32 GM-14788-01 to K.H. and National Institutes of Health grant HG00299 to D.H.

The publication costs of this article were defrayed in part by payment of page charges. This article must therefore be hereby marked "advertisement" in accordance with 18 USC section 1734 solely to indicate this fact.

\section{REFERENCES}

Aburatani, H., V.P. Stanton, and D.E. Housman. 1996. High resolution physical mapping by combined Alu-hybridization/STS content screening: Construction of a YAC contig covering $25 \mathrm{cM}$ in 3p21-p14. Proc. Natl. Acad. Sci. (in press). 


\section{HUNTER ET AL.}

Boyle, A.L., S.G. Ballard, and D.C. Ward. 1990. Differential distribution of long and short interspersed element sequences in the mouse genome: Chromosome karayotyping by fluorescence in situ hybridization. Proc. Natl. Acad. Sci. 87: 7757-7761.

Burke, D.T., G.T. Carle, and M.V. Olson. 1987. Cloning of large segments of exogenous DNA into yeast by means of artificial chromosome vectors. Science 236: $806-812$.

Chapman, V.M., N.G. Copeland, F.D. Costantini, W.F. Dove, J.H. Nadeau, R.H. Reeves, J. Rossant, O. Smithies, and R.P. Woychik. 1993. A plan for the mouse genome project. Mamm. Genome 4: 293-300.

Chartier, F.L., J.T. Keer, M.J. Sutcliffe, D.A. Henriques, P. Mileham, and S.D.M. Brown. 1992. Construction of a mouse yeast artificial chromosome library in a recombination-deficient strain of yeast. Nature Genet. 1: 132-136.

Chumakov, I., P. Rigault, S. Guillou, P. Ougen, A. Billaut, G. Guasconi, P. Gervy, I. LeGall, P. Soularue, L. Grinas et al. 1992. Continuum of overlapping clones spanning the entire human chromosome 22q. Nature 359: 380-387.

Cohen, D., I. Chumakov, and J. Weissenbach. 1993. A first-generation physical map of the human genome. Nature 366: 698-700.

Collins, F. and D. Galas. 1993. A new five year plan for the U.S. human genome project. Science 262: 43-46.

Copeland N.G., N.A. Jenkins, D.J. Gilbert, J.T. Eppig, J.C. Maltais, W.F. Dietrich, A. Weaver, S.E. Lincoln, R.G. Steen, L.D. Stein, J.H. Nadeau, and E.S. Lander. 1993. A genetic linkage map of the mouse: Current applications and future prospects. Science 262: 57-66.

Cornall, R.C., T.J. Aitman, C.M. Hearne, and J.A. Todd. 1991. The generation of a library of PCR-analyzed microsatellite variants for genetic mapping of the mouse genome. Genomics 10: 874-881.

Dietrich, W., H. Katz, S.E. Lincoln, H.-S. Shin, J. Friedman, N. Dracopoli, and E.S. Lander. 1992. A genetic map of the mouse suitable for typing intraspecific crosses. Genetics 131: 423-447.

Dietrich, W., J. Miller, H. Katz, D. Joyce, R. Steen, S. Lincoln, M. Daly, M.P. Reeve, A. Weaver, N. Goodman, N. Dracopoli, and E.S. Lander. 1993. SSLP genetic map of the mouse (Mus musculus) $2 \mathrm{~N}=40$. In Genetic maps, 6th ed. (ed. S. O'Brien), Chapter 4, pp. 110-142. Cold Spring Harbor Laboratory Press, Cold Spring Harbor, NY.

Dietrich W.F., J.C. Miller, R.G. Steen, M. Merchant, D. Damron, R. Nahf, A. Gross, D.C. Joyce, M. Wessel, R.D. Dredge et al. 1994. A genetic map of the mouse with 4,006 simple sequence length polymorphisms. Nature Genet. 7: 220-245.

Feinberg, A. and B. Vogelstein. 1984. A technique for radiolabelling DNA restriction endonuclease fragments to high specific activity. Anal. Biochem. 137: 266-267.

Foote, S., D. Vollrath, A. Hilton, and D.C. Page. 1992. The human Y chromosome: Overlapping DNA clones spanning the euchromatic region. Science 258: 60-66.

Gordenin, D.A., K.S. Lobachev, N.P. Degtyareva, A.L. Malkova, E. Perkins, and M.A. Resnick. 1993. Inverted DNA repeats: A source of eukaryotic genomic instability. Mol. Cell. Biol. 13: 5315-5322.

Hunter, K.W., M.L. Watson, J. Rochelle, S. Ontiveros, D. Munroe, M.F. Seldin, and D.E. Housman. 1993. Single-strand conformational polymorphism (SSCP) mapping of the mouse genome: Integration of the SSCP, microsatellite, and gene maps of mouse Chromosome 1. Genomics 18: 510-519.

Hunter, K.W., S.D. Ontiveros, M.L. Watson, V.P. Stanton Jr., P. Gutierrez, D. Bhat, J. Rochelle, S. Graw, C. Ton, M. Schalling, H. Aburatani, S.D.M. Brown, M.F. Seldin, and D.E. Houseman. 1994. Rapid and efficient construction of yeast artificial chromosome contigs in the mouse genome utilizing interspersed repetitive sequence (IRS-PCR): Generation of a $5 \mathrm{cM},>5$ megabase contig on mouse chromosome 1. Mamm. Genome 5: 597-607.

Kusumi, K., J.S. Smith, J.A. Segre, D.S. Koos, and E.S. Lander. 1993. Construction of a large-insert yeast artificial chromosome library of the mouse genome. Mamm. Genome 4: 391-392.

Larin, Z., A.P. Monaco., and H. Lehrach. 1991. Yeast artificial chromosome libraries containing large inserts from mouse and human DNA. Proc. Natl. Acad. Sci. 88: $4123-4127$.

Lisitsyn, N., N. Lisitsyn, and M. Wigler. 1993. Cloning the differences between two complex genomes. Science 259: 946-951.

Little, R.D., G. Pilia, S. Johnson, M. D'Urso, and D. Schlessinger. 1992. Yeast artificial chromosomes spanning 8 megabase and 10-15 centimorgans of human cytogenetic band Xq26. Proc. Natl. Acad. Sci. 89: $177-181$.

Lui, J., V.P. Stanton Jr., T.M. Fujiwara, J.-X. Wang, R. Rezonzew, M.J. Crumley, K. Morgan, P. Gros, D.E. Housman, and E. Schurr. 1995. Large-scale cloning of human chromosome 2-specific yeast artificial chromsomes (YACs) using an interspersed repetitive sequences (IRS)-PCR approach. Genomics 26: 178-191.

Manly, K. 1993. A MacIntosh program for storage and analysis of experimental genetic mapping data. Mamm. Genome 4: 303-313.

McCarthy, L., K. Hunter, L. Schalkwuk, L. Riba, S. Anson, R. Mott, W. Newell, C. Bruley, I. Bar, E. Ramu, D. Housman, R. Cox, and H. Lehrach. 1995. Efficient high resolution genetic mapping of mouse IRS-PCR products, 
towards integrated genetic and physical mapping of the mouse genome. Proc. Natl. Acad. Sci. 92: 5302-5306.

Mott, R., E. Grigoriev, E. Maier, J. Hoheisel, and H. Lehrach. 1993. Algorithims and software tools for ordering clone libraries: Application to the mapping of the genome of Schizosaccharomyces pombe. Nucleic Acids Res. 21: 1965-1974.

Murray, J.C., K.H. Buetow, J.L. Weber, S. Ludwigsen, T. Scherpbier-Heddema, F. Manion, J. Quillen, V.C. Sheffield, S. Sunden, G.M. Duyk et al. 1994. A comprehensive human linkage map with centimorgan density. Cooperative Human Linkage Center (CHLC). Science 265: 2049-2054

Nelson, D.L., S.A. Ledbetter, L. Corbo, M.F. Victoria, R. Ramierz-Solis, T.D. Webster, D.H. Ledbetter, and C.T. Caskey. 1989. Alu polymerase chain reaction: A method for rapid isolation of human-specific sequences from complex DNA sources. Proc. Natl. Acad. Sci.

86: 6686-6690.

Qin, S., S. Sait, J. Zhang, N. Nowak, Y. Cheng, L. Li, M. Higgens, D.J. Munroe, E. Bric, D.E. Housman, D. Gerhardt, G. Evans, B. Weber, P. Gaudary, and T. Shows. 1996. A YAC contig of human chromosome 11. Proc. Natl. Acad. Sci. (in press).

Ramu, E., L. Riba, D. Housman, and K. Hunter. 1996. Generation and mapping of $M$. spretus strain-specific markers for rapid genomic scanning. Mamm. Genome (in press).

Riley, J., R. Butler, D. Ogilivie, R. Finniear, D. Jenner, S. Powell, R. Anand, J.C. Smith, and A.F. Markham. 1990. A novel, rapid method for the isolation of terminal sequences from yeast artificial chromosome (YAC) clones. Nucleic Acids Res. 18: 2887-2890.

Rowe, L.B., J.H. Nadeau, R. Turner, W.N. Frankel, V.A. Letts, J.T. Eppig, M.S.H. Ko, S.J. Thurston, and E.H. Birkenmeier. 1994. Maps form two interspecific backcross DNA panels available as a community genetic mapping resource. Mamm. Genome 5: 253-274.

Schlessinger, D., R.D. Little, D. Freije, F. Abidi, I. Zucchi, G. Porta, G. Pilia, R. Nagaraja, S.K. Johnson, J.-Y. Yoon, A. Srivastava, J. Kere, G. Palmieri, A. Ciccodicola, V. Montanaro, G. Romano, A. Casamassimi, and M. D'Urso. 1991. Yeast artificial chromosome-based genome mapping: Some lessons from Xq24-28. Genomics 11: 783-793.

Vetrie, D., E. Kendall, A. Coffey, S. Hassock, J. Collins, C. Todd, H. Lehrach, M. Bobrow, D.R. Bentley, and A. Harris. 1994. A 6.5 Mb yeast artificial chromosome contig incorporating 33 DNA markers of the human $X$ chromosome at Xq22. Genomics 19: 42-47.

Watson, M.L., P. D'Eustachio, B.A. Mock, A.D. Steinberg, H.C. Morse III, R.J. Oakey, T.A. Howard, J.M. Rochelle, and M.F. Seldin. 1992. A linkage map of mouse Chromosome 1 using an interspecific cross segregating
IRS-PCR PHYSICAL MAPPING OF THE MOUSE GENOME

for the gld autoimmunity mutation. Mamm. Genome 2: $158-171$.

Received January 10, 1996; accepted in revised form February 26, 1996. 


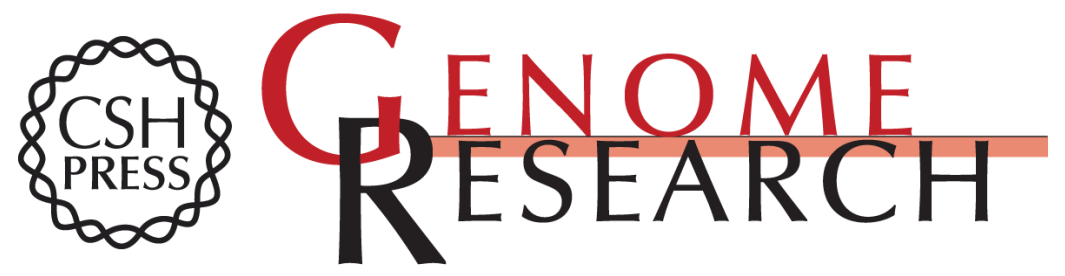

\section{Toward the construction of integrated physical and genetic maps of the mouse genome using interspersed repetitive sequence PCR (IRS-PCR) genomics.}

K W Hunter, L Riba, L Schalkwyk, et al.

Genome Res. 1996 6: 290-299

Access the most recent version at doi:10.1101/gr.6.4.290

References This article cites 31 articles, 13 of which can be accessed free at: http://genome.cshlp.org/content/6/4/290.full.html\#ref-list-1

\section{License}

Email Alerting

Receive free email alerts when new articles cite this article - sign up in the box at the Service top right corner of the article or click here.

\section{Affordable, Accurate Sequencing.}

To subscribe to Genome Research go to: https://genome.cshlp.org/subscriptions 